\title{
Relationship Between Emotional Intelligence And Job Satisfaction Among Health Workers
}

\author{
${ }^{* 1}$ Dr. Barnabas E. Nwankwo, ${ }^{2}$ Tobias C. Obi, ${ }^{3}$ Dr Ngozi Sydney-Agbor, \\ ${ }^{4}$ Solomon A. Agu, ${ }^{5}$ Dr. James U. Aboh \\ ${ }^{1,2}$ Department of Psychology, Caritas University, Enugu \\ ${ }^{3}$ Department of Psychology, Imo State University Owerri \\ ${ }^{4,5}$ Department of Psychology, Enugu State University of Science and Technology
}

\begin{abstract}
This study investigated the relationship between emotional intelligence and job satisfaction among health workers. A total of 116 participants comprising 45 doctors and 71 nurses were selected from National Orthopedic Hospital, Enugu State. They between the ages of 24 years-64 years with a mean age of 45 years. They were selected, making use of purposive stratified sampling technique. The participants were administered a 20-item Minnesota satisfaction questionnaire, 33-item emotional intelligence scale and 22-item Maslach Burnout Inventory. Here, regression analysis was applied as a statistical test to analyze the data. The findings revealed that there was a significant positive relationship between emotional intelligence and job satisfaction among health workers $(r=.67<0.01)$. This shows that as emotional intelligence increases, job satisfaction will increase.
\end{abstract}

Keywods: emotional intelligence, job satisfaction, nurses, medical doctors, nigerian health workers

\section{Introduction}

There is increasing evidence to suggest a positive relationship between physician's job satisfaction and patient's satisfaction as well as health outcomes, i.e. continuity of care and enhanced adherence to treatment. Interestingly, the "affective revolution", taking place in organizational context the last decades, has pointed out the importance of psychological constructs implicated in the process of job satisfaction (JS), such as Emotional Intelligence (EI) and Emotional Labor (EL). Although emotions constitute a common characteristic of human beings, each individual differs widely in the ability to monitor one's own and others' feelings and emotions, to discriminate among them and to use this information to guide one's thinking and actions (i.e. EI),. Mayer and Salovey, (1997) conceptualized four facets in EI: appraisal of emotion in self, recognition of emotion in others, regulation of emotion, and use of emotion to promote performance. Theoretical approaches were followed by the design of measures to assess the construct of EI. On the basis of the measurement method used to operationalize them, EI constructs can be categorized into trait EI (emotion-related self-perceived abilities and behavioral tendencies measured through self-report tests) and ability EI (emotion-related cognitive abilities that should be assessed via maximum-performance tests). Most scientific research in various fields is conducted within the framework of trait EI. Irrespective of the theoretical framework used for empirical data interpretation, self-report measures remain important as well as widely used tools in different scientific fields . EI has emerged as an interesting topic in social and organizational psychology and appears to play a critical role in key organizational outcomes, such as job performance and job satisfaction, especially when the focus is on human interaction. Importantly, in the health care setting, physicians who are more competent in recognizing emotions, concerns and needs of patients are more successful in treating them. Therefore, the interpersonal communication between the patient and the physician plays a major role in patient outcomes, and emotionally intelligent physicians consist of a valuable resource for hospitals. In the organizational psychology literature, much attention has been drawn to the positive association between EI and JS (the latter being defined as a pleasurable or positive emotional state resulting from the appraisal of one's job or job experiences. As supported by a wide range of studies in varied work environments, employees with higher EI are more satisfied with their job. Furthermore, research findings from the limited number of empirical studies examining the moderating role of gender in the EI-JS relationship are controversial. According to Petrides and Furnham, (2001) and Salim et al., (2012)gender does not moderate the path from EI to JS, whereas Afolabi et al., (2010) argue that EI and gender may interact to influence JS. The health profession requires frequent interaction with patients, careful analysis of occasionally very complex health issues, high decision latitude and high psychological demands. Also, as the number of health workers increases, competition in the health profession is growing, adding more pressure and stress to those working with the hospitals.

Job satisfaction is an attitude that people form towards their job or work environment by taking into account their feelings, believe and behaviors and describes to the extent to which they like their job (Spector 1997). The level of job satisfaction reflects and is affected by employees work experiences as well as their present situation 
and future expectations; job satisfaction is an attitude that is very sensitive to the features of the context in which it is studied. There is no model of job satisfaction applicable to all work settings as there are no general truths regarding the factors and mechanisms accounting for such an elusive and subjective concept. Most relevant theories consider satisfaction and dissatisfaction as the two poles of a continuum, with one increasing as the other diminishes. Herzberg (1966), however argued, they are independent phenomena, because the factors causing satisfaction are different from those causing dissatisfaction. He proposed a two factor model of motivating factors that are related to satisfaction and the hygiene factors which are related to dissatisfaction (Herzberg, Mausner \& Synderman, 1959). Motivating factors or motivators arise from intrinsic conditions of the job itself, such as achievement, interest about the job, recognition, responsibility, advancement, can lead to job satisfaction. Hygiene factors or dissatisfiers refer to extrinsic job characteristics, such as reasonable pay, security, pleasant work conditions, supervisory practices that if they are present at one's work, prevents one from experiencing dissatisfaction (Herzberg, 1966). According to Herzberg's dual factor motivation theory, the presence of gratifying job characteristics such as the previously mentioned motivators, can contribute to job satisfaction. Their absence, however, does appear to lead to unhappiness and job dissatisfaction. On the other hand, dissatisfaction results when a reasonable level of hygiene factor is not met. Again, abundance of such factors does not lead to higher job satisfaction, consequently, to increase job satisfaction and motivate an employee to higher performance, factors concerned with the nature of work itself (the motivators) should be taken into account, reducing dissatisfaction entails focusing on factors concerned with the job environment (Hertzberg, 1987). It is important to note that lack of job satisfaction is a predictor of quitting a job because job satisfaction is a reflection of the match between what workers want from their job and what they actually receive.

Emotional intelligence appears to play a significant role in key organization outcomes including stress and job satisfaction (Daus \& Ashkanasy, 2005). Empirical evidence suggests that certain components of EI influence or predict job satisfaction (Platsidou \& Agaliotis, 2008). Moreover, it is proposed that EI has a protective effect regarding occupational stress (Mikolajczak, Menil \& Luminet, 2007). Although the relationship between EI, and job satisfaction have been studied in several professions, less research has been carried out in the medical profession (McQueen, 2004). The present research aims at investigating the role of EI \& job satisfaction in predicting burnout among health workers.

Trait emotional intelligence (EI) concerns people's self-perceptions of their own emotional abilities and skills, personality characteristics and behavioral dispositions that influence their ability to cope successfully with environmental demands and pressure (Petrides, 2011). According to Petrides and his colleagues, the construct can alternatively be labeled as trait emotional self-efficacy; it is located at the lower levels if personality hierarchies and it is measured via self-reports (Petrides, Pita \& Kokkinaki, 2007). Research evidence has shown that EI is related, directly or indirectly, to better adjustment or success in academic, personal, social or occupational settings (Zeidner, Matthews \& Roberts, 2006). Also high EI is associated with lower levels of anxiety and depression (Bastian, Burns \& Nettlebeck, 2005), occupational stress (Bar-on, Brown, Brown, Kircaldy \& Thome, 2000) and burnout (Platsidou, 2010) and with higher levels of job satisfaction (Carmel, 2003). In some professions such as in mental health professionals (Nikolaou \& Tsaousis, 2002) and in teachers (Kafetsios \& Zampetakis, 2008), trait EI emerged as an important personality-level predictor of burnout and job satisfaction. Emotionally intelligent individuals can cope better with life's challenges and control their emotions more efficiently. Also, according to Sharma (2011), emotional intelligence is the ability of an individual to perceive access and manage emotions of his own that of others. Emotional intelligence is the driving force behind the factor that affect personal success and everyday interactions with others.

Emotional intelligence in health profession: The health profession demands that health workers, in the process of giving care, has to interact with the patients, the medical fraternity and health care workers constantly. This interaction is not just a conversation; it is a complex process that involves perception, understanding of the patient emotions and utilization of the perceptions to manage the patients' situations towards the goal of effective patient care (Sharma, 2011). The concept of emotional intelligence has grown in popularity among doctors and nurses over the last two decades, generating interest both at a social and a professional level, (Freshwater and Stickley, 2004). This study is geared towards examining the relationship between emotional intelligence and job satisfaction among health professional.

\section{HYPOTHESES}

The following hypothesis was tested:

1) There will be a significant positive relationship between emotional intelligence and job satisfaction among health workers 


\section{Design/Statistics}

\section{Methods}

A survey research design was adopted since the researcher did not manipulate any variable. Hence multiple analyses were used to analyze the data to test the hypothesis.

\section{Participants}

A total of 116 participants comprising of 52 male and 64 female health workers were selected. The participants were drawn from National Orthopedic Hospital, Enugu state. The participants comprises of 45 doctors and 71 nurses. The total number of male doctors: 35 , total number of female doctors: 10, total number of male nurses: 17 , total number of female nurses: 55 . The participants are between the ages of 24 years-67 years and mean age of 45 years. 71 participants were married while 45 were single. None of the participants have worked below 5 years.

\section{Instruments}

Two instruments were used in the study for the collection of data:

Job Satisfaction Scale

Minnesota Satisfaction Questionnaire developed by Weiss, Dawis, England, Lofquit (1967) was used. It is a 20 item questionnaire designed to examine certain prevailing situation in workplace. Three components of the fulfillment will be obtained with the inventory. They include; the inventory satisfaction, extrinsic satisfaction (E) and General satisfaction (G). The items were worked 1-very dissatisfied, 2 - dissatisfied, 3 - I am not sure, 4 - satisfied, 5 - very satisfied. Thus, a least score of 30 is obtainable as well as highest possible score of 89 could be obtainable by any given respondent. The questionnaire used was developed by Weiss, Dawis, England, Lofaquist (1967). The scales assess job satisfaction (job satisfactoriness) which is the fulfillment a worker derives from his/her input into the job environment the job environment provides a workers. Thus, we use this scale because it is most appropriate.

Scoring: The items are scored directly by adding together the values of the numbers shaded in the relevant items that constitute each of the three components. For example, if in items 7, 8, 9, 10, 11,12 the numbers that were marked were 3,2,4,5,1,2 respectively, the score for the six item is $3+2+4+5+1+2=17$ (addition of the marked numbers). For intrinsic satisfaction: I Items $=1,2,3,4,7,8,9,10,11,15,16,20$

For Extrinsic satisfaction: E items $=5,6,12,13,14,19$

For General satisfaction: $\mathrm{G}$ Items $=$ all the 20 items.

\section{Emotional Intelligence Scale (EIS)}

The Emotional Intelligence Scale (EIS) developed by Schutte, Marlouf, Hall, Harggerty copper, Golden \& Donhelm, (1998). The scale is a uni-dimensional scale that assesses emotional intelligence based on self report responses to 33 items tapping the appraisal and expression of emotions in self and others, regulations of emotions in self and others, and activations of emotion in solving problems. Participants responded by indicating their agreement to each of the 33 statements using a five-point scale ranging from 1 (strongly disagree) to 5 (strongly agree) since (EIS) contains 33 items, the total maximum of score is $33 \times 5=165$ and lowest is $33 \times 1=33$. The EIS has been used extensively in the southern part of the country with both adults (Adeyemo \& Ogunyemi, 2005) with Cronbach alpha of 0.93. And lastly, the content of the scale is culture-free and easy to understand; and found suitable for use with adolescents, Schutte, et al. (1998) some of the items of the scale are, "I know when to speak about my personal problems to others", "I find it hard to understand the non-verbal message of other people "I like to share my emotions with others", "By looking at their facial expressions I recognize the emotions people are experiencing",

\section{Procedure}

First and foremost the researcher was given permission by the research ethics of the hospital to conduct the research. After which a total of one hundred \& fifty copies (150) of the research questionnaire were distributed within a period of one week to the target population (health workers). The researcher distributed the questionnaires to the nurses in their various units while that of the doctors was done in the common room, taking into consideration purposive stratified sampling technique, where the available and wiling participants were used for the research. Finally, 116 copies of the questionnaire were used for the analysis; the scores were analyzed to test the hypothesis. 


\section{Results}

TABLE 1: Descriptive statistics and inter-correlations among the study variables (Emotional intelligence and job satisfaction).

\begin{tabular}{|c|c|c|c|c|}
\hline Variables & Mean & Std. deviation & 1 & 2 \\
\hline Emotional intelligence & 122.65 & 13.30 & 1 & \\
\hline Job satisfaction & 73.71 & 12.45 & .67 & 1 \\
\hline
\end{tabular}

Correlation is significant at the 0.01 level (2tailed).

The correlation table reveals that there is a positive significant correlation between emotional intelligence and job satisfaction $(\mathrm{r}=.67, \mathrm{P}<.01)$. However, the mean and standard deviations of the two predictor variable (emotional intelligence and job satisfaction) are as follows $(\mathrm{M}=1.2265, \mathrm{SD}=13.30$ and $\mathrm{M}=73.71, \mathrm{SD}=12.45)$ respectively. This result confirms the hypothesis that states that there will be a positive correlation between emotional intelligence and job satisfaction among health workers. It has been proven that emotional intelligence is positively correlated to job satisfaction.

\section{Discussion}

The outcome of this study indicates that the hypothesis tested in relation to the relationship between emotional intelligence and job satisfaction among health workers yielded positive relationship. Importantly, in the health care setting, physicians who are more competent in recognizing emotions, concerns and needs of patients are more successful in treating them. Therefore, the interpersonal communication between the patient and the physician plays a major role in patient outcomes, and emotionally intelligent physicians consist of a valuable resource for hospitals. This ability to exhibit high competence in recognizing and understanding patients emotions (emotional intelligence) surely will give the health worker some ample of increased level of job satisfaction.

\section{Implications of the Findings}

The outcome of this study would help to understand the relationship between emotional intelligence and job. From the result it is obvious that when a health worker has high emotional intelligence his/her level of job satisfaction will be high. This has a lot of implication in the workplace. This will ensure increased level of job satisfaction which is needed in the health sector because of the delicate nature of their work which deals with human lives. A disenchanted and dissatisfied health worker will most likely perform lower than required, thereby endangering the lives in his/her care.

\section{Limitations of the Study}

The use of self-report measures, which may result in response bias (e.g. social desirability, mood state) and in overstatement of the relationships between the examined constructs, does serve as limitations of the study. Furthermore, the adopted cross-sectional research design of our study renders difficult any interference about the causative nature of the examined relationships. Additionally, the power to detect moderators might have been decreased by the relatively small sample size, unequal sample sizes across groups (e.g. male vs. female), and possibly heterogeneous error variance. Other limitations of our study concern the collection of data from one hospital center and the relative brevity of the measures used

\section{Conclusion}

In the health sector, Emotional Quotient programs should be used to build organizational capacity for bringing out the best in people and forming powerful workplace relationships. This helps to increase engagement, trust and integrity to build more effective teams, retain great employees, provide exceptional customer care, and effectively manage change. Development of skills like communication skills, logical skills, comprehension skills, creative skills, and management skills must get priority.

Emotional intelligence test should be used in workplace for giving promotions, staff reviews, Recruitment. Based on the findings of this study it is hereby concluded that emotional intelligence and job satisfaction are significantly related among health workers. The employers should also organize forums and lectures that would possibly educate the employees in order to develop their emotional intelligence and be able to cope with different challenges; this way, less/no burnout will manifest. The employees should also undergo trainings/programs which would help them develop emotional intelligence and be able to manage their emotions and emotions of others. 


\section{REFERENCES}

[1]. Adeyemo, D.A \& Ogunyemi, B (2005) Emotional intelligence and self-efficacy as predictors of occupational stress among academic staff in Nigeria University, Nigeria. Unpublished manuscript.

[2]. Afolabi, O.A., Awosola, R.K., \& Omole, S.O. (2010). Influence of emotional intelligence and gender on Job performance and Job satisfaction among Nigerian policemen. Curr Res J Soc Sci, 2,147-154.

[3]. Bastian, V.A., Burns, N.R., \& Nettelbeck, T. (2005). Emotional Intelligence predicts life skills, but not as well as personality and Cognitive abilities. Personality and Individual Differences, 39, 1135-45.

[4]. Bar-on, R., Brown, J.M., Kircaldy, B.D., \& Thome, E.P. (2000). Emotional expression and implication of occupational stress: Application of the emotional quotient inventory. Personality and Individual Differences, 28, 1107-18.

[5]. Carmel, A. (2003). The relationship between emotional intelligence and work attitudes, behavior and outcomes. Journal of Management Psychology, 18, 788-813.

[6]. Daus, S., \& Ashkanasy, M. (2005). The case of an ability-based Model of emotional intelligence in organizational behavior. Journal of Organizational Behavior, 26, 453-466.

[7]. Freshwater, D., \& Stickley, T.(2004). The heart of the art.: emotional intelligence in nurse education. Nursing Inquiry, 11(2), 91-98.

[8]. Herzberg, F. (1966). Work and Nature of Man. Cleveland: World Publishing CO.

[9]. Herzberg. F., Mansuer, B., \& Snyderman, B.B. (1959). The Motivation to Work. New York: willey.

[10]. Kafetsios, K., \& Zampetakis, L.A. (2008). Emotional intelligence and Job satisfaction: Testing the mediatory role of positive and Negative affect at work. Personality and Individual Differences, 44, 712-722.

[11]. Mayer, J.D., \& Salovey, P. (1997). What is emotional intelligence? In Emotional Development and Emotional Intelligence: Implications for Educators. Edited by Salovey P, Sluyter D. New York: Basic Books; 3-31.

[12]. McQueen, A.C.H. (2004). Emotional intelligence in nursing work. Journal of Advanced Nursing, 47(1) 101-108.

[13]. Mikolajczak, M., Menil, C., \& Luminet, O. (2007). Explaining the Protective effect of trait emotional. International Journal of Law, Psychology and Human Life, 1 (1), 13-22.

[14]. Nikalaou, I., \& Tsaousis, I. (2002). Emotional intelligence in the work Place: Exploring its effect on occupational stress and Organizational commitment. The international journal of Organizational Analysis, 10 (4), 327-342.

[15]. Petrides, V. (2011). Ability and Trait Emotional Intelligence. The Blackwell-wiley Handbook of Individual Differences. New York: wiley.

[16]. Petrides, K.V., \& Furnham, A. (2001). Trait emotional intelligence: Psychometric investigation with reference to established trait taxonomies. Eur. J. Pers , 15, 425-448

[17]. Petrides, K.V., Pita R., \& Kokkinaki, F. (2007). The location of trait. Emotional Intelligence in Personality Factor Space. British journal of Psychology, 31 (1), 60-76.

[18]. Platsidou, M., \& Agaliotis, I. (2008). Burnout and Job Satisfaction and Instructional assignment- related sources of stress in Greek Special education teachers. International Journal of Disability, Development and Education, 55(1): 61-76.

[19]. Salim, S.S., Nasir, R., Arip, M., \& Mustafa, M. (2012). The role of emotional intelligence on job satisfaction among school teachers. The Social Sciences, 7, 125-129.

[20]. Spector,P.E. (1997). Job satisfaction: Application, Assessment, Causes and consequences. Thousand oaks C.A: Sage Publications Inc.

[21]. Schutte, N.S., Malouff, J.M., Hall, L.E., Haggerty, D.J., Cooper, J.T., Golden, C.J., \& Dornheim, L. (1998). Development and validation of Emotional Intelligence. Personality and Individual Differences, 25, 167-77.

[22]. Sharma, R. (2011). The Role of EQ \ Emotional Intelligence Competencies in Mental Well-being. Journal of Business Perspectives, 15 (2) $177-191$.

[23]. Zeidner, M., Matthews, G., \& Roberts, R.D. (2006). Emotional Intelligence, Adaption, and Coping, Emotional Intelligence in Everyday Life: a Scientific Inquiry (Second Edition) (pp. 100-125). Philadelphia, PA: Psychology Press. 